${ }^{1}$ Núcleo de Células-tronco e Terapia Celular, Departamento de Clínica e Cirurgia Veterinárias, Escola de Veterinária da Universidade Federal de Minas Gerais (UFMG)، Belo Horizonte, MG, Brasil ${ }^{2}$ Laboratório de Imunologia Celular e Molecular, Departamento de Bioquímica e Imunologia, Instituto de Ciências Biológicas, UFMG, Belo Horizonte, MG, Brasil
Correspondência para: Rogéria Serakides Núcleo de Células-tronco e Terapia Celular, Departamento de Clínica e Cirurgia Veterinárias, Escola de Veterinária, UFMG,

Av. Presidente Antônio Carlos, 6627 30161-970 - Belo Horizonte, MG, Brasil

serakidesufmg@gmail.com

Recebido em 17/Abr/2012 Aceito em 27/Out/2012

\section{Efeito in vitro da triiodotironina sob o potencial osteogênico reduzido de células-tronco mesenquimais do tecido adiposo de ratas ovariectomizadas e com osteoporose}

\author{
In vitro effects of triiodothyronine on the reduced osteogenic \\ potential of adipose tissue derived mesenchymal stem cells \\ from of ovariectomized rats and with osteoporosis
}

Jankerle Neves Boeloni', Natalia Melo Ocarino', Alfredo Miranda Goes', Rogéria Serakides'

\section{RESUMO}

Objetivo: Avaliar se a triiodotironina (T3) aumenta a diferenciação osteogênica das células-tronco mesenquimais do tecido adiposo (CTM-TA) de ratas adultas ovariectomizadas e com osteoporose e compará-lo ao de ratas adultas e jovens sem osteoporose. Materiais e métodos: CTM-TA foram cultivadas em meio osteogênico e distribuídas em sete grupos: 1) CTM-TA de ratas jovens sem osteoporose; 2) CTM-TA de ratas adultas sem osteoporose; 3) CTM-TA de ratas adultas com osteoporose e $4,5,6$ e 7) CTM-TA de ratas adultas com osteoporose tratadas comT3 $(0,01 \mathrm{nM}, 1 \mathrm{nM}, 100 \mathrm{nM}$ e 1.000 $\mathrm{nM})$. Avaliaram-se: atividade da fosfatase alcalina, conversão do dimetiltiazol (MTT), porcentagem de nódulos de mineralização, celularidade e quantificação de transcriptos gênicos para colágeno I, osteocalcina, osteopontina e Bmp-2. Resultados: Independente da dose, T3 reduziu a conversão do MTT, a atividade da fosfatase, a porcentagem de células e a expressão de colágeno I em pelo menos uma das doses e dos períodos estudados $(p<0,05)$. Mas o tratamento comT3 não alterou o número de nódulos de mineralização e a expressão de osteopontina e Bmp-2 em culturas de CTM-TA de ratas adultas com osteoporose $(p>0,05)$. Conclusão: T3 apresenta efeitos negativos sobre alguns fatores envolvidos na diferenciação osteogênica de CTM-TA, sem, no entanto, reduzir a formação de nódulos de mineralização e a expressão de proteínas ósseas. Arq Bras Endocrinol Metab. 2013;57(2):98-111

Descritores

Células-tronco mesenquimais; tecido adiposo visceral; diferenciação osteogênica; triiodotironina; osteoporose; ratas

\section{ABSTRACT}

Objective: To examine if triiodothyronine (T3) increases osteogenic differentiation adipose tissue derived stem cells (ASCs) from ovariectomized adult rats with osteoporosis compared with young rats and adult rats without osteoporosis. Materials and methods: The ASCs were cultured in osteogenic medium and distributed into seven groups: 1) ASCs of young rats without osteoporosis; 2) ASCs of adult rats without osteoporosis; 3 ) ASCs of adult rats with osteoporosis and 4, 5, 6 and 7) ASCs of adult rats with osteoporosis treated with $T 3(0.01 \mathrm{nM}, 1 \mathrm{nM}, 100 \mathrm{nM}$ and 1,000 nM). We analyzed alkaline phosphatase activity, dimethylthiazol (MTT) conversion, percentage of mineralized nodules, cellularity and quantification of gene transcripts for collagen I, osteocalcin, osteopontin and Bmp-2. Results: Regardless of the dose,T3 reduced the MTT conversion, alkaline phosphatase activity, percentage of cells and the expression of collagen I in at least one of the doses and periods studied $(p<0.05)$. But, the treatment with 3 does not modify the number of mineralized nodules and the expression of osteopontin and Bmp-2 in culture of ASCs from adult rats with osteoporosis ( $p>0.05$ ). Conclusion:T3 has a negative effect on some factors involved in osteogenic differentiation of ASCs from adult rats with osteoporosis, without; however, reduce the formation of mineralized nodules and the expression of bone proteins. Arq Bras Endocrinol Metab. 2013;57(2):98-111

\section{Keywords}

Mesenchymal stem cells; visceral adipose tissue; osteogenic differentiation; triiodothyronine; osteoporosis; female rats 


\section{INTRODUÇÃO}

$\mathrm{O}$

tecido adiposo fornece uma fonte rica e acessível de células-tronco mesenquimais (CTM-TA) e por isso pode apresentar enorme potencial para terapia autóloga de várias doenças degenerativas. A perda do potencial osteogênico das CTM-TA, em decorrência de alguns fatores inerentes ao doador, como idade e doença, ainda é muito controversa e precisa ser mais bem elucidada. As CTM-TA, tanto do tecido subcutâneo quanto da cavidade abdominal (visceral), tem sido alvo de diversas pesquisas, inclusive no que concerne ao implante destas em defeitos ósseos (1-4). Essas células, à semelhança das CTM da medula óssea (CTM-MO), também podem se diferenciar em vários tipos celulares $(5,6)$ como em células da linhagem adipogênica, miogênica, condrogênica e osteogênica $(5,7)$.

A diferenciação osteogênica das CTM-TA é influenciada por diversos fatores como estrógeno $(8,9)$, vitamina D (10), ácido retinoico (10-12), BMP-2 (11-13), fator de crescimento semelhante à insulina 1 (IGF-1) (14), fator de crescimento de transformação $\beta$ (TGF- $\beta$ ) (15), oncostatina M (16) e pelo estímulo mecânico (17). O efeito positivo da T3 na diferenciação osteogênica tem sido pesquisado nas CTM-MO de ratas jovens e saudáveis (18). Em CTM do tecido adiposo, tanto subcutâneo quanto visceral, foi comprovada a presença de receptores para os hormônios tireoidianos (19). Mas o que se sabe é que a tiroxina (T4) aumenta a síntese de IGF em culturas de CTM-TA de suínos, favorecendo a adipogênese (20). O efeito da T3 na diferenciação osteogênica das CTM-TA ainda não é conhecido.

Pelo fato de a diferenciação osteogênica da ser também influenciada positivamente pelo estrógeno (8), postulou-se, no presente estudo, que as CTM-TA de ratas ovariectomizadas apresentam redução da diferenciação osteogênica, o que limitaria o uso dessa fonte de célula no tratamento da osteoporose. Por isso, o objetivo inicial deste estudo foi verificar se as CTM-TA de ratas ovariectomizadas e com osteoporose apresentam redução do potencial osteogênico e estudar o efeito de diferentes doses da T3 na diferenciação osteogênica dessas células.

\section{MATERIAIS E MÉTODOS}

\section{Ovariectomia e indução da osteoporose}

Foram utilizadas 12 ratas Wistar com dois meses de idade alojadas em caixas plásticas, numa proporção de seis ratas/caixa, recebendo ração comercial ( $1,4 \%$ de cálcio, $0,60 \%$ de fósforo e $22 \%$ de proteína) e água ad libitum. As ratas foram mantidas em um regime de 12 horas de luz e 12 horas no escuro e foram separadas inicialmente em dois grupos, sendo um grupo não ovariectomizado (normal, $\mathrm{n}=6$ ) e um grupo ovariectomizado (OVX, $\mathrm{n}=6$ ). As ratas do grupo ovariectomizado foram submetidas à ovariectomia bilateral sob anestesia geral (associação de $40 \mathrm{mg} / \mathrm{kg}$ de quetamina com $10 \mathrm{~g} / \mathrm{kg}$ de xilazina). A remoção dos ovários foi feita por duas incisões laterodorsais de aproximadamente um centímetro de extensão na região abdominal com exteriorização das gônadas, ligadura dos cornos uterinos e posterior sutura da parede abdominal e da pele com fio categute e sutura padrão em ponto simples separado. Todos os procedimentos descritos a seguir foram aprovados pelo Comitê de Ética em Experimentação Animal da Universidade Federal de Minas Gerais (UFMG) (protocolo $\left.\mathrm{n}^{\mathrm{o}} 134 / 2008\right)$.

Três meses após a ovariectomia, tempo suficiente para a indução da osteoporose (21) que foi comprovada pela análise histomorfométrica (dados não demonstrados), os animais foram submetidos à eutanásia com sobredose de anestesia (associação de $40 \mathrm{mg} / \mathrm{kg}$ de quetamina com $10 \mathrm{~g} / \mathrm{kg}$ de xilazina). O tecido adiposo visceral (omento) foi colhido para extração e determinação do potencial osteogênico das CTM.

\section{Extração e cultivo de células-tronco mesenquimais do tecido adiposo visceral}

A extração das CTM-TA foi realizada conforme protocolos já estabelecidos $(7,22)$. Foi colhido, assepticamente, o tecido adiposo visceral de ratas adultas com e sem osteoporose e de ratas jovens saudáveis. No fluxo laminar, inicialmente, realizaram-se a remoção dos pelos e a antissepsia na pele da região abdominal ventral com posterior laparotomia para colheita do tecido adiposo abdominal. O tecido adiposo foi colhido em DMEM (Dulbecco's Modified Eagle Medium) enriquecido com gentamicina $(60 \mu \mathrm{g} / \mathrm{L})$, penicilina $(100 \mathrm{U} / \mathrm{mL})$, estreptomicina $(100 \mu \mathrm{g} / \mathrm{mL})$ e anfotericina $(25 \mu \mathrm{g} / \mathrm{L})$ (Sigma Aldrich, St. Louis, MO, USA). Em seguida, o tecido, cortado em pequenos fragmentos, foi transferido para um tubo com colagenase $0,15 \%$ (Sigma Aldrich, St. Louis, MO, USA) diluída em PBS (solução tampão de fosfato padrão) $0,15 \mathrm{M}$ e incubado por 60 minutos a $37^{\circ} \mathrm{C}$ e $5 \%$ de $\mathrm{CO}_{2}$, agitando-o de 15 em 15 minutos. Após a incubação, a colagenase foi inativada pela adição de DMEM com 10\% SFB (soro 
fetal bovino - LGC Biotecnologia, São Paulo, Brasil). Posteriormente, fez-se a centrifugação por 10 minutos a $1.400 \mathrm{~g}$, obtendo-se três fases: gordura, hemáceas e outras células sanguíneas e precipitado (fase estromal). O sobrenadante foi descartado e o precipitado foi ressuspenso em DMEM enriquecido com antibióticos e antimicóticos mais $10 \%$ SFB e cultivado em garrafas T75 em estufa a $37^{\circ} \mathrm{C}$ e $5 \%$ de $\mathrm{CO}_{2}$. O meio de cultivo foi trocado duas vezes por semana. Após quatro repiques e até que se obteve a confluência de $80 \%$ a $90 \%$ das células, foi realizada a caracterização fenotípica das CTM-TA por citometria de fluxo.

As CTM-TA das ratas adultas ( 5 meses de idade) com e sem osteoporose e das ratas jovens (1 mês de idade) foram cultivadas em meio de indiferenciação (DMEM) e de diferenciação osteogênico, descrito à frente, acrescido ou não de 3,3',5-triiodo-L-tironina (T3 - Sigma-Aldrich, St. Louis, MO, USA), dependendo do grupo. Foram constituídos sete grupos experimentais de CTM-TA cultivadas em meio osteogênico: 1) CTM-TA de ratas jovens sem osteoporose; 2) CTM-TA de ratas adultas sem osteoporose; 3 ) CTM-TA de ratas adultas com osteoporose sem T3; 4) CTM-TA de ratas adultas com osteoporose tratadas com T3 $(0,01 \mathrm{nM}) ; 5)$ CTM-TA de ratas adultas com osteoporose tratadas com T3 (1 nM); 6) CTM-TA de ratas adultas com osteoporose tratadas com T3 (100 nM) e 7) CTM-TA de ratas adultas com osteoporose tratadas com T3 (1.000 nM). Foram avaliados: atividade da fosfatase alcalina, conversão do substrato dimetiltiazol (MTT) em cristais de formazan, expressão de colágeno I, osteocalcina, osteopontina e de Bmp-2, por RT-PCR em tempo real, e número de nódulos de mineralização aos sete, 14 e 21 dias de diferenciação e celularidade aos 21 dias de diferenciação. Todos os ensaios in vitro foram realizados com seis repetições em cada grupo e em cada período como descrito detalhadamente a seguir.

\section{Caracterização fenotípica das células-tronco mesenquimais do tecido adiposo visceral}

Após o cultivo em garrafas T75 das CTM-TA em DMEM por quatro passagens e obtenção de confluência de $80 \%$ a $90 \%$, as células das ratas jovens e adultas com e sem osteoporose foram tripsinizadas, contadas em câmara de Neubauer e distribuídas em placas de 96 poços com fundo redondo (TPP - Techno Plastic Products in Trasadingen, Switzerland, Germany) com concentração de 1 x $10^{6}$ células/poço, sendo um poço para cada anticorpo e um poço para o controle sem marcação para cada grupo experimental. Esse ensaio foi realizado em duplicata. Posteriormente, foi realizada a centrifugação da placa por 10 minutos a $1.400 \mathrm{~g}$ e $10^{\circ} \mathrm{C}$, seguida da retirada do sobrenadante (DMEM) e adição de $2 \mu \mathrm{L}$ do anticorpo primário e $20 \mu \mathrm{L}$ de PBS $0,15 \mathrm{M} /$ poço. A placa foi agitada em vórtex e incubada por 30 minutos a $4^{\circ} \mathrm{C}$. Adicionaram-se $150 \mu \mathrm{L}$ de PBS $0,15 \mathrm{M}$ /poço para lavagem e a placa foi novamente agitada em vórtex. A placa foi, então, centrifugada por 10 minutos a $1.400 \mathrm{~g} \mathrm{e} 10^{\circ} \mathrm{C}$, seguida da retirada do sobrenadante e de nova lavagem com $150 \mu \mathrm{L}$ de PBS $0,15 \mathrm{M} /$ poço, agitação em vórtex e centrifugação por 10 minutos a $1.400 \mathrm{~g} \mathrm{e} 10^{\circ} \mathrm{C}$. Adicionou-se o anticorpo secundário (Alexa Flúor 488, Molecular Probes, Oregon, USA) com diluição de 1:200. A placa foi envolta por papel alumínio e incubada por 30 minutos a $4^{\circ} \mathrm{C}$. Posteriormente, adicionaram-se $150 \mu \mathrm{L}$ de PBS 0,15 $\mathrm{M}$ /poço para lavagem e agitação em vórtex. A placa foi centrifugada por 10 minutos a $1.400 \mathrm{~g} \mathrm{e} 10^{\circ} \mathrm{C}$, seguida da retirada do sobrenadante, de nova lavagem com 150 $\mu \mathrm{L}$ de PBS $0,15 \mathrm{M}$ /poço e centrifugação por $10 \mathrm{minu}$ tos a $1.400 \mathrm{~g}$ e $10^{\circ} \mathrm{C}$. Após a centrifugação, as células foram ressuspensas em $100 \mu \mathrm{L}$ de PBS 0,15 M e $100 \mu \mathrm{L}$ de formaldeído a $4 \%$. A leitura e as análises foram realizadas em um citômetro de fluxo FACScan (Fluorescence Activated Cell Analyser - FACScan, Becton Dicknson Immunocytometry, San Jose, CA, USA) empregando o software Cell Quest (The Cell QuestTM Software, Becton Dickinson Dicknson Immunocytometry Systems, San Jose, CA, USA), com aquisição de 20.000 eventos, tendo como parâmetros FSC (Forward scatter) e SSC (Side scatter) em escala linear e FLl (fluorescência relativa) em escala logarítmica que detecta luz de comprimento de onda de $530 \mathrm{~nm}$, que corresponde a fluorescência verde, para análises pelo programa WinMDI por gráficos de dot plot e histogramas (23). Os anticorpos primários utilizados foram: anti-CD45 (clone 69 mouse), anti-CD54 (clone 1A29 mouse), anti-CD73 (clone $5 \mathrm{~F} / \mathrm{B} 9$ mouse) e anti-CD90 (clone Ox-7 mouse) (BD Biosciences, San Jose, CA, USA).

\section{Extração e cultivo de osteoblastos}

A extração de osteoblastos da calvária foi realizada conforme protocolo já estabelecido (24). A calvária de ratos Wistar neonatos com dois dias de idade foi colhida assepticamente em fluxo laminar, para obtenção dos os- 
teoblastos. Inicialmente, realizou-se antissepsia da pele que recobre a cabeça, seguida do corte e colheita dos ossos frontais e parietais. Os fragmentos foram lavados em PBS, recortados em fragmentos pequenos e incubados em tripsina $1 \%$ por 15 minutos e posteriormente em colagenase $0,25 \%$ (Type I, Sigma Aldrich, St. Louis, MO, USA) diluída em PBS $0,15 \mathrm{M}$ por 60 minutos a $37^{\circ} \mathrm{C}$ e $5 \%$ de $\mathrm{CO}_{2}$. As células foram lavadas com $\mathrm{PBS}$ e, após centrifugação por 10 minutos a $1.400 \mathrm{~g}$, foram cultivadas em garrafas T75 (TPP - Techno Plastic Products in Trasadingen, Switzerland, Germany) contendo DMEM enriquecido com gentamicina $(60 \mu \mathrm{g} / \mathrm{L})$, penicilina $(100 \mathrm{U} / \mathrm{mL})$, estreptomicina $(100 \mathrm{mg} / \mathrm{mL})$ e anfotericina $(25 \mathrm{mg} / \mathrm{L})$ e $10 \%$ de soro fetal bovino em estufa a $37^{\circ} \mathrm{C}$ e $5 \%$ de $\mathrm{CO}_{2}$. O meio de cultivo foi trocado duas vezes por semana. Após quatro repiques e até que se obteve a confluência de $80 \%$ a $90 \%$ das células, estas foram utilizadas para extração do RNA total e posterior análise da expressão de proteínas colagênicas e não colagênicas pela técnica de RT-PCR em tempo real e, assim, usadas como controle positivo de células diferenciadas.

\section{Teste de viabilidade celular pelo azul de Tripan}

Após a caracterização fenotípica e antes do cultivo em meio de diferenciação, as CTM-TA de cada grupo experimental foram avaliadas quanto à viabilidade celular pelo azul de Tripan. Inicialmente, as CTM-TA foram cultivadas em garrafas T75 $\left(1 \times 10^{4}\right.$ células $\left./ \mathrm{cm}^{2}\right)$ com DMEM e, no momento do teste, lavadas com PBS $(0,15 \mathrm{M})$ e tripsinizadas. As células foram colhidas, centrifugadas a $1.400 \mathrm{~g}$ por 10 minutos, ressuspensas em meio e coradas pelo azul de Tripan. As células de cada grupo inviáveis (em azul) e viáveis (transparentes) foram quantificadas em câmara de Neubauer.

\section{Cultivo de células-tronco mesenquimais do tecido adiposo visceral em meio de diferenciação osteogênico}

Após o cultivo em DMEM e obtenção de confluência das células de $80 \%$ a $90 \%$, o meio foi substituído por meio osteogênico constituído por DMEM e enriquecido com ácido ascórbico $(50 \mathrm{mg} / \mathrm{mL})$, B-glicerofosfato $(10 \mathrm{mM})$ e dexametasona $(0,1 \mathrm{mM})$, acrescido de $10 \%$ de soro fetal bovino. As células foram mantidas em estufa a $37^{\circ} \mathrm{C}$ e $5 \%$ de $\mathrm{CO}_{2}$. Assim, as CTM-TA das ratas adultas com e sem osteoporose e jovens foram cultivadas em uma densidade previamente padronizada ( $1 \mathrm{x}$
$10^{4}$ células $\left./ \mathrm{cm}^{2}\right)$, em seis repetições, em garrafas T25 e em placas de 6 e 24 poços (TPP - Techno Plastic Products in Trasadingen, Switzerland, Germany), dependendo do teste, durante sete, 14 e 21 dias, sendo que as CTM-TA de ratas adultas com osteoporose foram cultivadas ainda com diferentes doses de 3,3',5-triiodo-L-tironina $(0,01 ; 1,0 ; 100$ e $1000 \mathrm{nM})$. As doses de $3,3^{\prime}, 5$-triiodo-L-tironina foram estabelecidas conforme estudos realizados por Boeloni e cols. (18) e por Ishida e cols. (25), sendo a dose de $0,01 \mathrm{nM}$ semelhante à dose fisiológica.

\section{Teste de conversão do MTT em cristais de formazan}

Foram cultivadas 1 x $10^{4} \mathrm{CTM}-\mathrm{TA} / \mathrm{cm}^{2}$ de cada grupo em seis repetições, em placas de 24 poços com meio osteogênico, acrescido ou não de diferentes doses de 3,3',5-triiodo-L-tironina ( 0,$01 ; 1,0 ; 100$ e $1.000 \mathrm{nM})$, dependendo do grupo experimental, durante sete, $14 \mathrm{e}$ 21 dias. Ao término de cada período, as culturas foram submetidas ao teste de conversão do MTT \{brometo de [3-(4,5-dimetiltiazol-2yl)-2,5-difenil tetrazolium]\} em cristais de formazan. O meio foi substituído por $210 \mu \mathrm{L}$ de meio osteogênico com soro fetal bovino em cada poço e $170 \mu \mathrm{L}$ de MTT $(5 \mathrm{mg} / \mathrm{mL}$ ) (Invitrogen, Carlsbad, CA, USA). A placa foi incubada por duas horas em estufa a $37^{\circ} \mathrm{C}$ e $5 \%$ de $\mathrm{CO}_{2}$. Os cristais de formazan foram observados ao microscópio antes do acréscimo de $210 \mu \mathrm{L}$ de SDS (sódio dodecil sulfato)- $10 \% \mathrm{HCl}$ que permaneceu overnight em estufa a $37^{\circ} \mathrm{C}$ e $5 \%$ de $\mathrm{CO}_{2}$. Posteriormente, $100 \mu \mathrm{L} /$ poço foram transferidos para placas de 96 poços para análise na leitora de placas com comprimento de onda de $595 \mathrm{~nm}$ de acordo com Valério e cols. (24).

\section{Avaliação da atividade da fosfatase alcalina}

Foram cultivadas 1 x $10^{4} \mathrm{CTM}-\mathrm{TA} / \mathrm{cm}^{2}$ de cada grupo em seis repetições, em placas de 24 poços com meio osteogênico, acrescido ou não de diferentes doses de 3,3',5-triiodo-L-tironina ( 0,$01 ; 1,0 ; 100$ e $1000 \mathrm{nM})$, dependendo do grupo experimental, durante sete, 14 e 21 dias. Ao término de cada período, as culturas foram lavadas com PBS (0,15 molar). Em cada poço, foram acrescentados $200 \mu \mathrm{L}$ de solução de BCIT/ NBT (Zymed Laboratories, CA, USA) (1 mL de tampão da fosfatase alcalina, $4,4 \mu \mathrm{L}$ de NBT \{nitro-blue tetrazolium chloride $\}$ e $3,3 \mathrm{~mL}$ de BCIP $\{5$-bromo-4-chloro-3'-indolylphosphate p-toluidine salt $\})$. As amostras ficaram duas horas na estufa a $37^{\circ} \mathrm{C}$ e $5 \%$ de $\mathrm{CO}_{2} \mathrm{e}$ 
foram posteriormente fotografadas. Em seguida, foram adicionados $210 \mu \mathrm{L}$ de solução detergente SDS $10 \%$ para incubação overnigth. Posteriormente, $100 \mu \mathrm{L}$ foram transferidos para placas de 96 poços para leitura em espectrofotômetro com comprimento de onda de $595 \mathrm{~nm}$ de acordo com Boeloni e cols. (18) e Ocarino e cols. (26).

\section{Determinação da porcentagem de células/campo}

Foram cultivadas $1 \times 10^{4} \mathrm{CTM} / \mathrm{cm}^{2}$ de cada grupo em seis repetições, em placas de 6 poços com lamínulas $(22$ x $22 \mathrm{~mm}$ ) estéreis com meio osteogênico, acrescido ou não de diferentes doses de 3,3',5-triiodo-L-tironina $(0,01 ; 1,0 ; 100$ e $1000 \mathrm{nM})$, dependendo do grupo experimental, durante 21 dias. Ao término desse período, as culturas foram fixadas em álcool $70 \%$ e submetidas à coloração por hematoxilina-eosina (27). Posteriormente, foi determinado o número de células/campo com o auxílio de uma ocular micrométrica, contendo uma gratícula com 121 pontos e objetiva de $20 \mathrm{x} \mathrm{em} 40$ campos tomados em toda a extensão da lamínula e objetiva de $20 x$.

\section{Avaliação da porcentagem de nódulos de mineralização}

Foram cultivadas $1 \times 10^{4} \mathrm{CTM}-\mathrm{TA} / \mathrm{cm}^{2}$ de cada grupo em seis repetições, em placas de 6 poços com lamínulas $(22 \times 22 \mathrm{~mm})$ estéreis, com meio osteogênico, acrescido ou não de diferentes doses de 3,3',5-triiodo-L-tironina $(0,01 ; 1,0 ; 100$ e $1.000 \mathrm{nM})$, dependendo do grupo experimental, durante sete, 14 e 21 dias. Ao término de cada período, as CTM-TA foram lavadas com PBS 0,15M e fixadas com álcool 70\% por 24 horas e coradas pelo método de Von Kossa (adaptada de 27) para avaliação da porcentagem de nódulos/campo. Somente os nódulos de coloração marrom ou negra foram avaliados. Foi determinada a porcentagem de nódulos/ campo com o auxílio de uma ocular micrométrica, contendo uma gratícula com 121 pontos em 50 campos em objetiva de 20x de acordo com Ocarino e cols. (28).

\section{Quantificação relativa dos transcritos gênicos para colágeno I, osteocalcina, osteopontina e Bmp-2 por RT-PCR em tempo real}

Realizou-se, em todos os grupos e nos três períodos estudados, a avaliação da quantificação relativa da expressão de colágeno I, osteocalcina, osteopontina e
Bmp-2 pela técnica de RT-PCR em tempo real. A extração do RNA total das células foi feita em três garrafas T25 por grupo pelo uso do Trizol (Invitrogen, USA). O método de extração consistiu de uma etapa inicial de lise e homogeneização da monocamada de células por cinco minutos à temperatura ambiente, para completa dissociação dos complexos nucleoproteicos. O lisado foi transferido para um microtubo de $1,5 \mathrm{~mL}$ e foi adicionado $0,2 \mathrm{~mL}$ de clorofórmio, seguido de 15 segundos de homogeneização, três minutos de incubação à temperatura ambiente e centrifugação a $12.000 \mathrm{~g}$ por 15 minutos a $4^{\circ} \mathrm{C}$, para separação em três fases, em que a fase incolor superficial continha o RNA. Na terceira etapa, a fase aquosa foi transferida para um novo tubo, com a adição de $0,5 \mathrm{~mL}$ de álcool isopropílico e incubação por 10 minutos à temperatura ambiente, seguida de centrifugação a 12.000 g por 10 minutos a $4{ }^{\circ} \mathrm{C}$ para precipitação do RNA. O pellet foi, então, lavado com $1 \mathrm{~mL}$ de etanol a $75 \%$, homogeneizado e centrifugado a $7.500 \mathrm{~g}$ por cinco minutos a $4^{\circ} \mathrm{C}$. O RNA foi solubilizado em água DEPC (água tratada com dimetil pirocarbonato, Invitrogen, USA) livre de RNAse e imediatamente armazenado a $-80^{\circ} \mathrm{C}$. A concentração de RNA de cada grupo foi determinada pela leitura da absorbância a 260/280 nm por espectrofotometria. Foram realizadas as reações de transcrição reversa utilizando-se kit comercial $\left(\mathrm{Su}^{-}\right.$ perScriptTM III Platinum ${ }^{\circledR}$ Two-Step qRT-PCR Kit with SYBR Green, Invitrogen, CA, USA), sendo que se utilizou $1 \mu \mathrm{g}$ de RNA total para a síntese de cDNA com um volume final de $20 \mu \mathrm{L}$. Realizaram-se, ainda, as reações de PCR em tempo real utilizando-se 2 $\mu \mathrm{g}$ de cDNA, 5 pM de cada iniciador e $12,5 \mu \mathrm{L}$ do reagente syber Green (SuperScriptTM III Platinum ${ }^{\circledR}$ Two-Step qRT-PCR Kit with SYBR Green, Invitrogen, CA, USA) em um volume final de $25 \mu \mathrm{L}$ de reação, no aparelho SmartCycler System (SmartCycler ${ }^{\circledR}$ System, Cepheid, Sunnyvale, CA, USA). Os parâmetros utilizados para amplificação foram: $50^{\circ} \mathrm{C}$ por 120 segundos, $95^{\circ} \mathrm{C}$ por 150 segundos e 45 ciclos de $95^{\circ} \mathrm{C}$ por 15 segundos e $60^{\circ} \mathrm{C}$ por 30 segundos. Os iniciadores foram delineados com base na sequência do mRNA Rattus norvegicus (Tabela 1). A expressão gênica foi calculada usando o método $2^{-\Delta \Delta \mathrm{CT}}$, em que os resultados obtidos para cada grupo foram comparados quantitativamente após a normalização baseada na expressão de gliceraldeído-3-fosfato desidrogenase (GAPDH) Rattus norvegicus. 
Tabela 1. Lista de genes e sequência de nucleotídeos dos iniciadores para RT-PCR em tempo real

\begin{tabular}{lll}
\hline Gene & \multicolumn{1}{c}{$\begin{array}{c}\text { Iniciadores (sequências de } \\
\text { nucleotideos 5' a 3') }\end{array}$} & No acesso \\
\hline GAPDH & $\begin{array}{l}\text { foward: CAACTCCCTCAAGATTGTCAGCAA } \\
\text { reverse: GGCATGGACTGTGGTCATGA } \\
\text { foward: GCAAGGTGTTGTGCGATGACG }\end{array}$ & NM_002046 \\
& Neverse: GGGAGACCACGAGGACCAGAG & \\
Osteocalcina & $\begin{array}{l}\text { foward: CATCTATGGCACCACCGTTT } \\
\text { reverse: AGAGAGAGGGAACAGGGAGG }\end{array}$ & NM_013414.1 \\
Osteopontina & $\begin{array}{l}\text { foward: ATCTCACCATTCCGATGAATCT } \\
\text { reverse: TCAGTCCATAAGCCAAGCTATCA }\end{array}$ & AB001382 \\
Bmp-2 & $\begin{array}{l}\text { forward: TAGTGACTTTGGCCACGACG } \\
\text { reverse: GCTTCCGTGTTTGTTTG }\end{array}$ & NM_017178 \\
\hline
\end{tabular}

\section{Análise estatística}

O delineamento foi multifatorial $(7 \times 3)$, ou seja, sete grupos e três períodos. Realizou-se análise de variância (ANOVA) e, para cada variável, foram determinados a média e o desvio-padrão. As médias foram comparadas pelo teste de SNK (Student Newman Keuls) utilizando o programa Graphpad Instat 3 (GraphPad Software Inc., San Diego, USA). As alterações na expressão medidas pelo RT-PCR em tempo real foram comparadas pelo teste de SNK após transformação logarítmica dos dados. Diferenças foram consideradas significativas se $\mathrm{p}<0,05$ (29).

\section{RESULTADOS}

\section{Caracterização fenotípica das células-tronco mesenquimais do tecido adiposo visceral}

As características fenotípicas das células extraídas do tecido adiposo de ratas adultas com e sem osteoporose e de ratas jovens sem osteoporose foram compatíveis com as de células-tronco. Houve expressão de CD45 em, no máximo, 6,34\% das células e expressão para CD54, CD73 e CD90 acima de $52,03 \%, 81,80 \%$ e $78,98 \%$ das células, respectivamente (Tabela 2 ).

Tabela 2. Caracterização fenotípica pela expressão de CD45, CD54, CD73 e CD90 por citometria de fluxo em células-tronco mesenquimais do tecido adiposo de ratas jovens e adultas sem osteoporose e adultas com osteoporose, cultivadas em DMEM após quatro repiques e confluência de $80 \%$ a $90 \%$

\begin{tabular}{lllll}
\hline \multirow{2}{*}{ Grupos } & \multicolumn{4}{c}{$\begin{array}{c}\text { Expressão de moléculas de } \\
\text { superfície (\%) }\end{array}$} \\
\cline { 2 - 5 } & CD45 & CD54 & CD73 & CD90 \\
\hline Jovem sem osteoporose (1 mês de idade) & 3,04 & 91,90 & 99,24 & 90,26 \\
Adulto sem osteoporose (5 meses de idade) & 4,69 & 52,03 & 81,80 & 78,98 \\
Adulto com osteoporose (5 meses de idade) & 6,34 & 80,19 & 85,94 & 85,83 \\
\hline
\end{tabular}

\section{Viabilidade celular pelo azul de Tripan}

Após a caracterização fenotípica e antes do cultivo em meio de diferenciação osteogênico, as CTM de todos os grupos apresentavam 100\% de viabilidade.

\section{Conversão do MTT em cristais de formazan}

Em comparação às CTM-TA das ratas jovens, as células das ratas adultas sem osteoporose apresentaram menor conversão do MTT em formazan nos três períodos avaliados. As CTM-TA das ratas OVX e com osteoporose sem tratamento com T3 apresentaram menor conversão do MTT em comparação às CTM-TA de ratas adultas sem osteoporose aos sete e 14 dias. O tratamento hormonal com T3 não aumentou a conversão do MTT em formazan em nenhuma das doses e dos períodos estudados. Ao contrário, as doses de 0,01 e $1 \mathrm{nM}$ de T3 reduziram a conversão do MTT pelas CTM-TA das ratas OVX e com osteoporose aos 14 e 21 dias e a dose de $1.000 \mathrm{nM}$ reduziu a conversão aos 21 dias quando comparadas às CTM-TA das ratas OVX e com osteoporose sem tratamento (Figura 1 ).

\section{Atividade da fosfatase alcalina (BCIP/NBT)}

Assim como no resultado do MTT, o efeito da idade sobre a atividade da fosfatase alcalina também foi observado em todos os períodos estudados, uma vez que as CTM-TA das ratas adultas sem osteoporose apresentaram atividade da fosfatase alcalina significativamente menor em comparação à das CTM-TA de ratas jovens aos sete, 14 e 21 dias. A osteoporose diminuiu a atividade da fosfatase alcalina somente aos sete dias. O tratamento com T3 não aumentou a atividade da fosfatase alcalina das CTM-TA de ratas adultas com osteoporose. Ao contrário, o efeito foi negativo, ou seja, caracterizado pela redução da atividade da fosfatase alcalina na dose de $1 \mathrm{nM}$ aos 21 dias (Figura 2).

\section{Porcentagem de células/campo}

As CTM-TA das ratas adultas sem osteoporose apresentaram celularidade significativamente menor em comparação à das CTM-TA das ratas jovens aos 21 dias, reafirmando o efeito da idade. Ratas OVX e com osteoporose também apresentaram redução da porcentagem de CTM-TA. Ao contrário do que se esperava, mais uma vez o tratamento com T3 não surtiu efeito positivo. A porcentagem de CTM-TA de ratas adultas com osteoporose reduziu significativamente nas doses de 0,01 e $1.000 \mathrm{nM}$ aos 21 dias (Figura 3). 
Redução do MTT
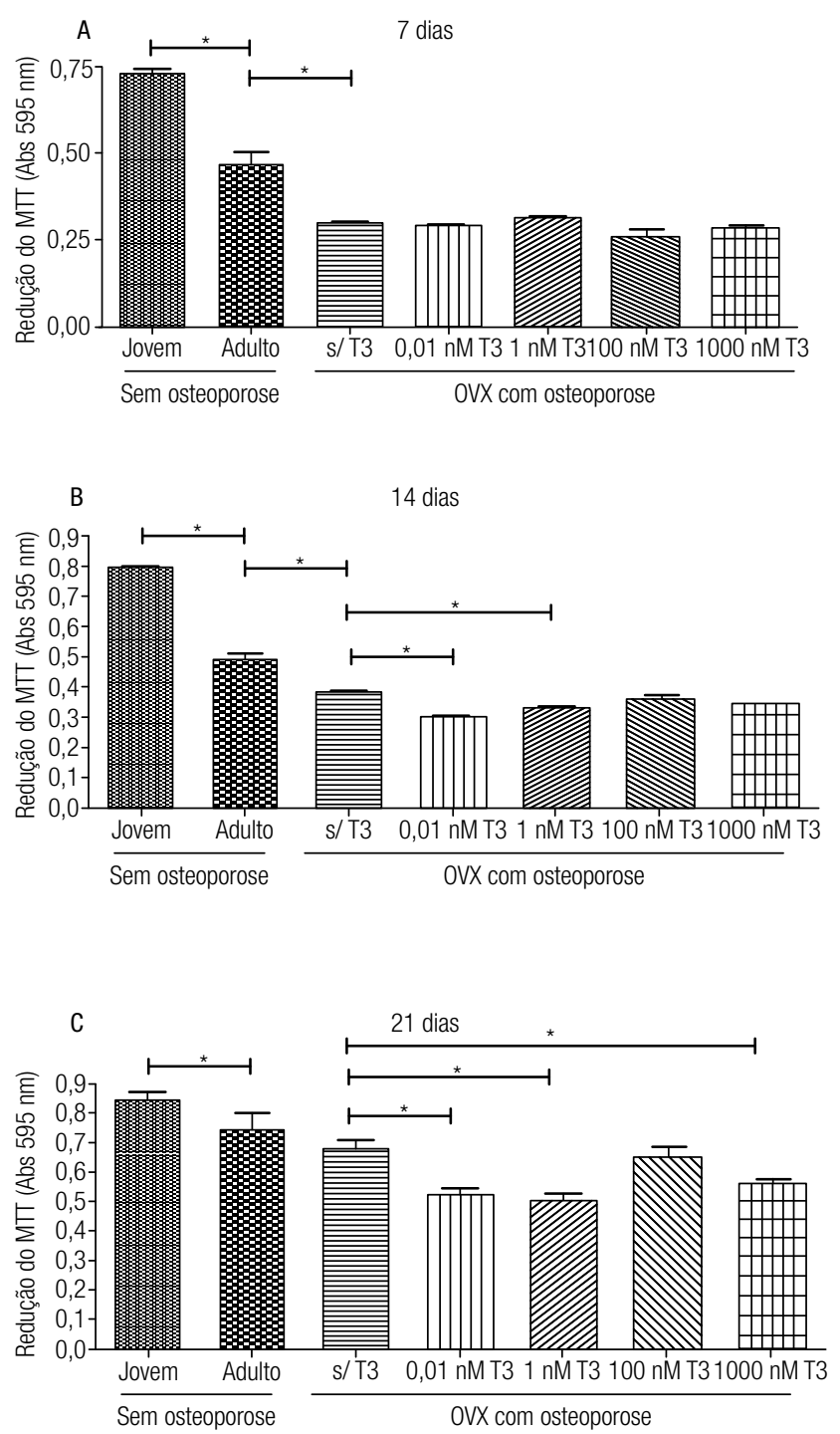

Figura 1. Conversão do MTT em cristais de formazan (média \pm desviopadrão) em culturas de CTM do tecido adiposo de ratas jovens e adultas sem osteoporose e ratas adultas com osteoporose tratadas ou não com T3 em meio de diferenciação osteogênico aos sete (A), 14 (B) e 21 (C) dias de cultivo. * $p<0,05$.

\section{Porcentagem de nódulos de mineralização}

O efeito da idade mais uma vez foi evidenciado sobre a síntese de nódulos de mineralização, já que a cultura de CTM-TA de ratas adultas apresentou número de nódulos de mineralização significativamente menor nos três períodos avaliados em comparação às culturas de células de ratas jovens. CTM-TA de ratas OVX e com osteopo-


Figura 2. Atividade da fosfatase alcalina (média \pm desvio-padrão) em culturas de CTM do tecido adiposo de ratas jovens e adultas sem osteoporose e ratas adultas com osteoporose tratadas ou não com T3 em meio de diferenciação osteogênico aos sete (A), 14 (B) e 21 (C) dias de cultivo. * $p<0,05$.

rose também apresentaram redução significativa do número de nódulos de mineralização em comparação às culturas de CTM-TA de ratas adultas sem osteoporose aos sete e 14 dias. No entanto, o tratamento com T3 não alterou esse resultado, já que o número de nódulos de mineralização nos grupos tratados, independentemente da dose de T3, foi semelhante ao das CTM-TA de ratas com osteoporose sem tratamento (Figura 4). 


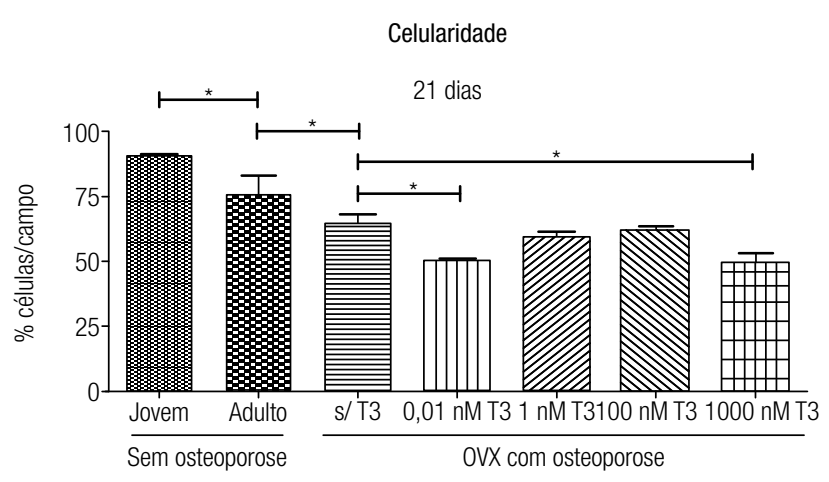

Figura 3. Porcentagem de células/campo (média \pm desvio-padrão) em culturas de CTM do tecido adiposo de ratas jovens e adultas sem osteoporose e ratas adultas com osteoporose tratadas ou não com T3 em meio de diferenciação osteogênico aos 21 dias de cultivo. * $p<0,05$.
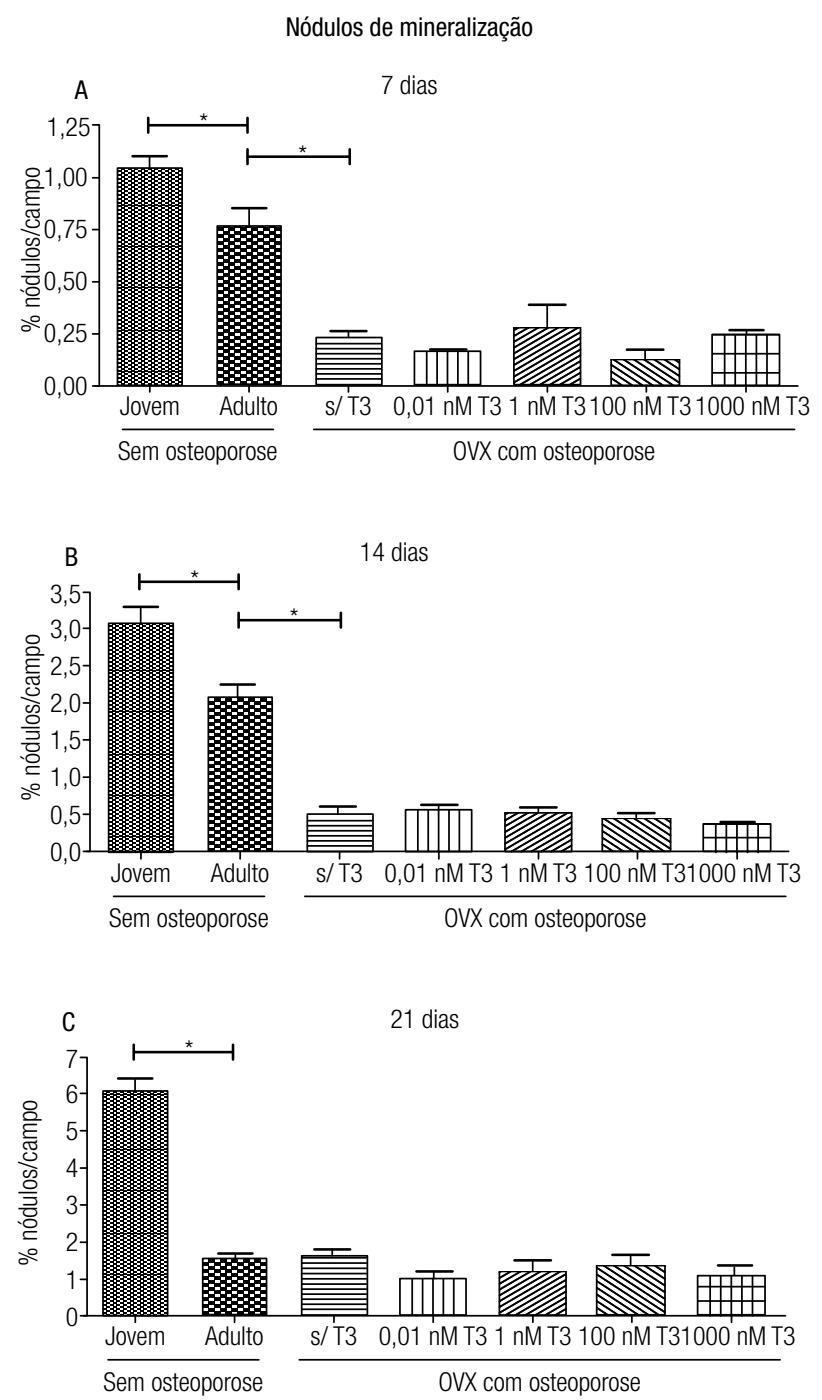

Figura 4. Porcentagem de nódulos de mineralização/campo (média \pm desvio-padrão) em culturas de CTM do tecido adiposo de ratas jovens e adultas sem osteoporose e de ratas adultas com osteoporose tratadas ou não com T3 em meio de diferenciação osteogênico aos sete $(\mathbf{A}), 14$ (B) e 21 (C) dias de cultivo. * $p<0,05$.
Expressão de colágeno I, osteocalcina, osteopontina e Bmp-2

A expressão dos transcritos gênicos para colágeno I, osteocalcina, osteopontina e Bmp-2 nas culturas das CTM-TA dos sete grupos foi comparada entre si e com a expressão em osteoblastos (controle positivo da diferenciação osteogênica).

A expressão de colágeno I, aos sete dias de diferenciação, foi superior à do osteoblasto em todos os grupos estudados (Figura 5). Entretanto, aos 14 e 21 dias de diferenciação essa expressão foi superior à do osteoblasto na maioria dos grupos estudados, com exceção do grupo de CTM-TA de ratas adultas sem osteoporose aos 14 e 21 dias e dos grupos de CTM-TA de ratas adultas com osteoporose tratadas com 100 e $1.000 \mathrm{nM}$ de $\mathrm{T} 3$ aos 21 dias (Figura 5).

$\mathrm{O}$ efeito da idade não foi evidenciado sobre a expressão de colágeno I, já que a cultura de CTM-TA de ratas adultas sem osteoporose apresentou expressão semelhante à cultura de células de ratas jovens nos três períodos de diferenciação. Mas CTM-TA de ratas OVX e com osteoporose apresentou expressão de colágeno I significativamente menor aos sete e 14 dias em comparação às culturas de CTM-TA de ratas adultas sem osteoporose (Figuras 5A e 5B). O tratamento com T3 das CTM-TA de ratas adultas com osteoporose não surtiu efeito positivo sobre a expressão de colágeno I. Ao contrário, as doses de 0,01 e $1.000 \mathrm{nM}$ de T3 reduziram significativamente aos 14 dias, à expressão de colágeno I quando comparado às CTM-TA de ratas OVX e com osteoporose sem tratamento (Figura 5).

A expressão de osteocalcina, nos três períodos avaliados, foi inferior a do osteoblasto em todos os grupos (Figura 6). Além disso, não houve efeito da idade sobre a expressão de osteocalcina. Ratas OVX e com osteoporose também não apresentaram alteração da expressão de osteocalcina quando comparadas às ratas adultas sem osteoporose. No entanto, aos sete dias de diferenciação, o tratamento com $0,01 \mathrm{nM}$ de T3 elevou significativamente a expressão de osteocalcina em comparação às CTM-TA de ratas com osteoporose sem tratamento (Figura 6).

Ao contrário da expressão de osteocalcina, o efeito da idade sobre a expressão de osteopontina foi marcante, já que a cultura de CTM-TA de ratas adultas apresentou expressão significativamente menor em comparação às culturas de células de ratas jovens em todos os períodos estudados (Figura 7). Entretanto, as CTM-TA 

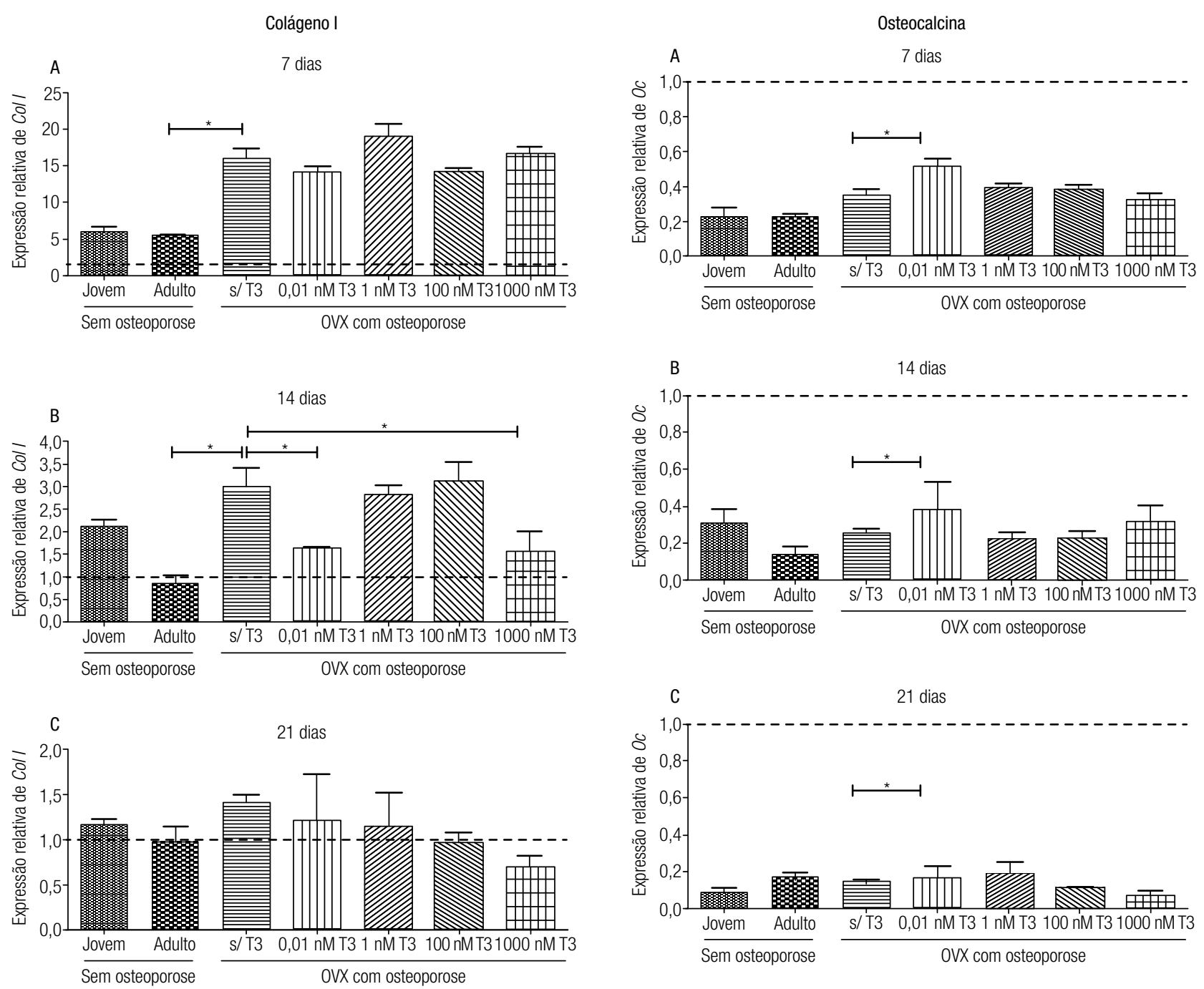

Figura 5. Quantificação relativa (média \pm desvio-padrão) do transcrito gênico para colágeno I (Col I) pela técnica de RT-PCR em tempo real em culturas de CTM do tecido adiposo de ratas jovens e adultas sem osteoporose e de ratas adultas com osteoporose tratadas ou não com T3 em meio de diferenciação osteogênico aos sete (A), 14 (B) e 21 dias (C) de diferenciação. Os dados estão expressos em relação ao osteoblasto (linha tracejada). * $p<0,05$.

de ratas OVX com osteoporose não apresentaram alteração significativa da expressão de osteopontina nos três períodos de diferenciação em comparação às CTM de ratas adultas sem osteoporose. O tratamento com T3 também não surtiu efeito positivo em nenhum dos períodos estudados (Figura 7).

A expressão de $B m p-2$, aos sete dias de diferenciação, foi superior a do osteoblasto somente no grupo de CTM-TA de ratas adultas sem osteoporose. Aos 14 dias de diferenciação, essa expressão foi superior à do osteoblasto nas CTM-TA de ratas adultas sem osteoporose e

Figura 6. Quantificação relativa (média \pm desvio-padrão) do transcrito gênico para osteocalcina $(0 c)$ pela técnica de RT-PCR em tempo real em culturas de CTM do tecido adiposo de ratas jovens e adultas sem osteoporose e de ratas adultas com osteoporose tratadas ou não com T3 em meio de diferenciação osteogênico aos sete (A), 14 (B) e 21 dias (C) de diferenciação. Os dados estão expressos em relação ao osteoblasto (linha tracejada). * $p<0,05$.

nas CTM-TA de ratas OVX e com osteoporose tratadas com 100 e $1.000 \mathrm{nM}$ de T3. Aos 21 dias de diferenciação, a expressão de $B m p-2$ foi superior à do osteoblasto nas CTM-TA de ratas adultas sem osteoporose e de ratas OVX e com osteoporose (Figura 8).

$\mathrm{O}$ efeito da idade também foi observado na expressão de $B m p-2$. No entanto, ao contrário dos parâmetros anteriormente descritos, a expressão de $B m p-2$ foi superior nas CTM-TA de ratas adultas sem osteoporose nos três períodos estudados quando comparada à de ratas jovens. CTM-TA de ratas OVX e com osteopo- 

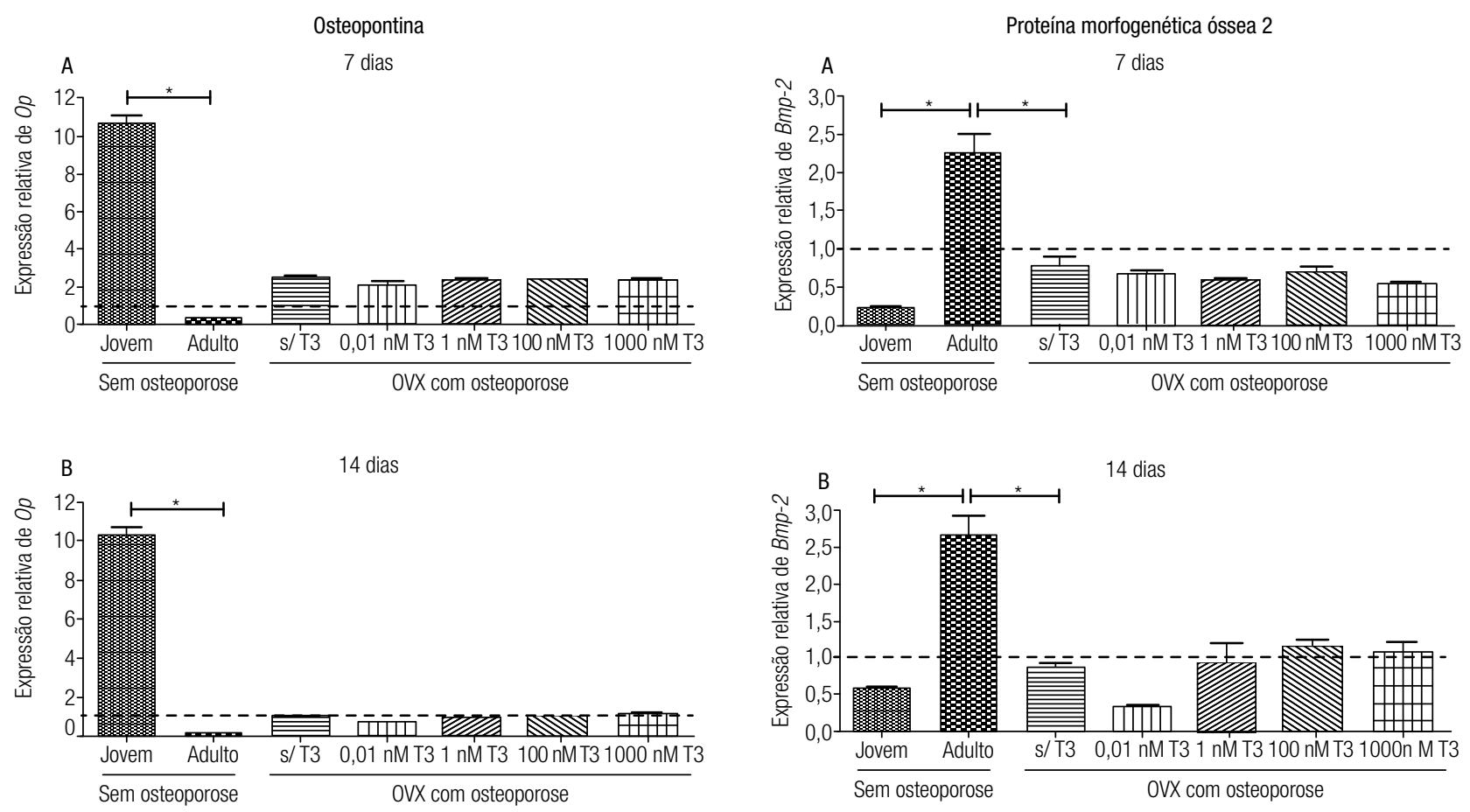

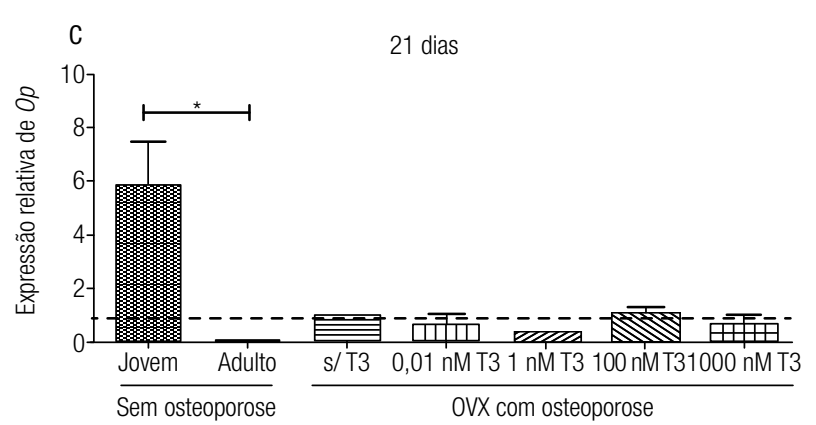

Figura 7. Quantificação relativa (média \pm desvio-padrão) do transcrito gênico para osteopontina $(O p)$ pela técnica de RT-PCR em tempo real em culturas de CTM do tecido adiposo de ratas jovens e adultas sem osteoporose e de ratas adultas com osteoporose tratadas ou não com T3 em meio de diferenciação osteogênico aos sete (A), 14 (B) e 21 dias (C) de diferenciação. Os dados estão expressos em relação ao osteoblasto (linha tracejada). * $p<0,05$.

rose apresentaram redução significativa da expressão de Bmp-2 aos sete e 14 dias, em comparação às CTM-TA de ratas adultas sem osteoporose. O tratamento com T3 das CTM-TA de ratas adultas OVX e com osteoporose não surtiu nenhum efeito significativo sob a expressão de $B m p-2$ (Figura 8).

\section{DISCUSSÃO}

A caracterização fenotípica das células demonstrou que, independente do grupo, as células apresentaram carac-

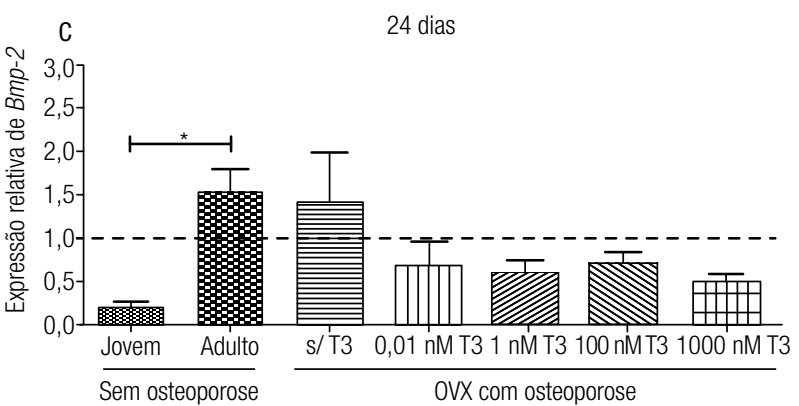

Figura 8. Quantificação relativa (média \pm desvio-padrão) do transcrito gênico para proteína morfogenética óssea $2(B m p-2)$ pela técnica de RT-PCR em tempo real em culturas de CTM do tecido adiposo de ratas jovens e adultas sem osteoporose e de ratas adultas com osteoporose tratadas ou não com T3 em meio de diferenciação osteogênico aos sete (A), 14 (B) e 21 dias (C) de diferenciação. Os dados estão expressos em relação ao osteoblasto (linha tracejada). * $p<0,05$.

terísticas compatíveis com a de células-tronco, ou seja, entre outras moléculas expressaram CD54, CD73 e CD90 e quase não expressaram CD45. Essa caracterização é importante, pois a fração estromal vascular extraída do tecido adiposo contém CTM-TA, células endoteliais, pericitos, fibroblastos e células hematopoiéticas (5). O "Mesenchymal and Tissue Stem Cell Committee of the International Society for Cellular Therapy" propôs que as CTM expressam CD73 e CD90 e não expressam CD45 (30). As células hematopoiéticas expressam, entre outras moléculas, CD45 (31), que também pode 
ser expressa em fibroblastos (23). CD54 (ICAM-1) não é exclusivo de CTM e pode ser expresso em baixas concentrações em leucócitos e células endoteliais (32). A despeito disso, leucócitos e outras células hematopoiéticas não são aderentes em superfícies plásticas, ao contrário das CTM (33). Adicionalmente, no tecido adiposo somente as CTM apresentam capacidade de diferenciação osteogênica (7).

Semelhante ao observado nas CTM-MO, o efeito da idade também reduziu a diferenciação osteogênica das CTM-TA. Com relação às CTM-MO, a literatura é quase unânime em afirmar que a idade reduz a diferenciação osteogênica dessas células (34-39). Mas com relação às CTM-TA, há controvérsia no que concerne ao efeito da idade sob a diferenciação osteogênica dessas células. Sabe-se que com a idade ocorre redução da diferenciação osteogênica de CTM-TA do subcutâneo de seres humanos (40), enquanto, em camundongos, foi demonstrado que o potencial osteogênico de CTM-TA visceral não diminui com a idade (41). Outros fatores além da idade, como a espécie e o local de onde é removido o tecido adiposo, podem influenciar no potencial de diferenciação das CTM-TA. Já foi demonstrado que, em coelhos, as CTM-TA da cavidade abdominal apresentam maior potencial de diferenciação osteogênica do que as CTM-TA do subcutâneo (42). Mas o contrário se observa em humanos, em que as CTM-TA do subcutâneo é que apresentam maior potencial de diferenciação (43). Além disso, também já foi comprovado que pode haver diferença no potencial osteogênico entre espécies. As CTM-TA de cães parecem ter maior capacidade proliferativa, enquanto as CTM-TA de seres humanos apresentam maior potencial osteogênico (44).

A expressão de $B m p-2$ foi o único parâmetro que aumentou com a idade em todos os três períodos estudados. Com base na literatura e no presente estudo fica difícil explicar a razão do aumento da expressão de Bmp-2 decorrente da idade. A BMP-2 é um fator importante na diferenciação osteogênica das CTM (1113). Então, seria esperado que as CTM-TA de ratas adultas saudáveis não apresentassem redução tão significativa nos parâmetros que caracterizam a diferenciação osteogênica como observado, neste caso, em comparação às ratas jovens. Contudo, estudos recentes enfatizam que a BMP-2 pode não influenciar a diferenciação osteogênica das CTM-TA $(45,46)$. No entanto, outros estudos demonstraram exatamente o contrário, ou seja, que a BMP-2 pode aumentar a atividade da fosfatase alcalina, a síntese de nódulos de mineralização (47) e a expressão de Runx2 e de osteocalcina em culturas de CTM-TA tratadas com BMP-2 (48).

Resultado interessante foi observado nas CTM-TA de ratas OVX e com osteoporose. Nas CTM-TA dessas ratas, houve redução da diferenciação osteogênica caracterizada por redução da atividade da fosfatase alcalina, da formação dos nódulos de mineralização e da expressão de $B m p-2$ em pelo menos um dos períodos estudados quando comparadas às CTM-TA de ratas sem osteoporose. Sabe-se que as CTM-TA apresentam receptores para o estrógeno (49) e que a adição de estrógeno em culturas de CTM-TA visceral de ratas jovens saudáveis (9) e de CTM-TA do subcutâneo de seres humanos saudáveis aumenta a diferenciação osteogênica dessas células (8). Assim, seria esperado que a deficiência de estrógeno causasse redução da diferenciação osteogênica das CTM-TA. Diante dessa hipótese, os resultados apresentados neste estudo não surpreendem. No entanto, existem relatos de que a diferenciação osteogênica de CTM-TA subcutâneo é mantida em camundongos SAMP 6 com osteoporose (50). É provável que a redução do potencial osteogênico das CTM-TA de camundongos SAMP 6 não tenha sido observada, uma vez que essa linhagem de camundongos apresenta aumento do comprimento do telômero e da expressão e da atividade da telomerase, ao contrário das ratas utilizadas no presente estudo que, com cinco meses de idade, já apresentam redução da expressão de telomerase (39). Além disso, ao contrário do estudo de Mirsaidi e cols. (50) no qual a osteoporose é decorrente de manipulação genética, no presente estudo, a osteoporose foi induzida pela deficiência dos esteroides sexuais, que é a causa mais frequente de osteoporose na mulher e que direta ou indiretamente pode afetar a diferenciação osteogênica das CTM (51). Dessa forma, a deficiência dos hormônios sexuais pode não ser o único fator que diminui a diferenciação osteogênica das CTM-TA de ratas OVX, já que existem outros fatores como vitamina $\mathrm{D}$ (10), ácido retinoico (10-12), BMP-2 (11-13), IGF-1 (14), TGF- $\beta$ (15) e leptina (52) que influenciam a diferenciação osteogênica e que podem estar reduzidos em indivíduos com deficiência de esteroides sexuais $(53,54)$.

No caso da CTM-TA, a redução da diferenciação osteogênica é provavelmente resultado direto ou indireto da deficiência dos hormônios sexuais. No entanto, no caso das CTM-MO, a redução da diferenciação osteogênica, além de ser resultante da deficiência dos esteroides sexuais, poderia também ser resultante da 
própria osteoporose, uma vez que no microambiente da medula óssea há forte interação e relação entre os diferentes tipos celulares e a matriz extracelular com o comportamento das CTM-MO. A matriz extracelular parece ser importante no controle da proliferação e da diferenciação das CTM em resposta a fatores apropriados. Além disso, ela modula a atividade de fatores de crescimento, como o TGF- $\beta$, e sequestra fatores tais como o fator de crescimento derivado das plaquetas $(\mathrm{PDGF})$ e as BMP. Proteínas Wnt, que pertencem à família de ligantes, ligam-se aos glicosaminoglicanos da matriz extracelular e regulam a diferenciação osteogênica das CTM (55). Sendo assim, no caso das CTM-MO não somente a perda do potencial osteogênico pode ser um dos fatores envolvidos na gênese da osteoporose, como a própria osteoporose, que se caracteriza por redução da matriz extracelular e que pode comprometer a diferenciação osteogênica das CTM-MO.

Outro objetivo deste estudo foi verificar se a redução da diferenciação osteogênica apresentada pelas CTM-TA decorrente da osteoporose poderia ser revertida pela adição de T3 na cultura. Mas, surpreendentemente e contrariando todas as assertivas anteriores, o tratamento com T3 não aumentou a diferenciação osteogênica das CTM-TA de ratas OVX e com osteoporose.

Os efeitos biológicos da T3 que resultam em estimulação da transcrição gênica são mediados por receptores nucleares da superfamília de receptores esteroides. Esses receptores são compostos por duas isoformas principais: TR $\alpha$ e TR $\beta$ subdivididas em nove isoformas (TR $\alpha 1, \alpha 2, \alpha 3, \Delta \alpha 1, \Delta \alpha 2, \beta 1, \beta 2, \beta 3$ e $\Delta \beta 3$ ). As três isoformas funcionais foram identificadas como TR $\alpha$ l, $\operatorname{TR} \beta 1$ e TR $\beta 2$ e são os receptores nucleares que induzem a transcrição gênica. As isoformas do receptor não funcionais podem atuar como antagonistas dos receptores verdadeiros de T3 (56). Poderia se pensar que a presença de maior quantidade de receptores (TR $\alpha)$ para hormônios tireoidianos no tecido adiposo subcutâneo em comparação ao tecido adiposo visceral de pacientes obesos (19) poderia explicar o porquê de não ter ocorrido aumento da diferenciação osteogênica, uma vez que a fonte de CTM-TA desse estudo foi o tecido adiposo visceral. No entanto, seria interessante investigar também a presença de outras isoformas de receptores e comparar com a expressão desses receptores nas células-tronco do tecido adiposo e da medula óssea na tentativa de compreender por que os resultados da adição de T3 em culturas de CTM-TA são diferentes das culturas de CTM-MO (18).
Outra provável explicação para a diferença do efeito de T3 observada nas CTM-TA deste estudo em comparação as CTM-MO (18) pode ser que, no caso do tecido ósseo, a importância dos hormônios tireoidianos in vivo recai sobre a diferenciação e a atividade dos osteoblastos para a síntese da matriz óssea, bem como seu envolvimento em todo o metabolismo ósseo. No entanto, no caso do tecido adiposo, os hormônios tireoidianos regulam, in vivo, a expressão do gene da adiponectina que, por sua vez, está envolvida no metabolismo de lipídios e carboidratos (56). Outra razão provável seria que, no tecido adiposo, os hormônios tireoidianos estejam mais envolvidos com a adipogênese, já que foi comprovado que a T4 aumenta a síntese de IGF em culturas de CTM-TA de suínos, favorecendo a adipogênese (20). Assim, pode ser que, pela distinta função que T3 e T4 tenham no osso e no tecido adiposo, esses hormônios também tenham efeitos distintos sob a diferenciação osteogênica das CTM-TA quando comparada à CTM-MO. Porém, mais estudos são necessários para comprovar essa hipótese e verificar as razões pelas quais T3 tem efeitos distintos sobre a diferenciação osteogênica das CTM do tecido adiposo e da medula óssea de ratas OVX e com osteoporose.

Conclui-se que o aumento da idade e a ovariectomia reduzem a diferenciação osteogênica das CTM-TA de ratas e que o tratamento com T3 não melhora o potencial de diferenciação reduzido das CTM-TA de ratas OVX e com osteoporose. Ao contrário, o tratamento com T3 apresenta efeitos negativos sobre alguns dos fatores envolvidos na diferenciação osteogênica, sem, no entanto, reduzir a formação de nódulos de mineralização.

Agradecimentos: ao apoio financeiro concedido pela Fundação de Amparo à Pesquisa do Estado de Minas Gerais (Fapemig) e pelo Conselho Nacional de Desenvolvimento Científico e Tecnológico $(\mathrm{CNPq})$.

Declaração: os autores declaram não haver conflitos de interesse científico neste estudo.

\section{REFERÊNCIAS}

1. Li H, Dai K, Tang T, Zhang X, Yan M, Lou J. Bone regeneration by implantation of adipose-derived stromal cells expressing BMP-2. Biochem Biophys Res Commun. 2007;356:836-42.

2. Arthur A, Zannettino A, Gronthos S. The therapeutic applications of multipotential mesenchymal/stromal stem cells in skeletal tissue repair. J Cell Phisiol. 2009;218:237-45.

3. Rada T, Reis RL, Gomes ME. Adipose tissue-derived stem cells and their application in bone and cartilage tissue engineering. Tissue Eng. 2009;15:113-25. 
4. Levi B, Longaker MT. Adipose derived stromal cells for skeletal regenerative medicine. Stem Cells. 2011;29:576-82.

5. Zuk PA, Zhu M, Ashjian P, De Ugarte DA, Huang JI, Mizuno H, et al. Human adipose tissue is a source of multipotent stem cells. Mol Biol Cell. 2002;13:4279-95.

6. Planat-Benard V, Silvestre JS, Cousin B, André M, Nibbelink M, Tamarat $\mathrm{R}$, et al. Plasticity of human adipose lineage cells toward endothelial cells: physiological and therapeutic perspectives. Circulation. 2004;109:656-63.

7. Zuk PA, Zhu M, Mizuno H, Huang J, Futrell JW, Katz AJ, et al. Multilineage cells from human adipose tissue: implications for cell-based therapies. Tissue Eng. 2001;7:211-28.

8. Hong L, Colpan A, Peptan IA, Daw J, George A, Evans CA. 17- $\beta$ estradiol enhances osteogenic and adipogenic differentiation of human adipose-derived stromal cells. Tissue Eng. 2007;13:1197-203.

9. Taskiran D, Evren V. Stimulatory effect of $17 \beta$-estradiol on osteogenic differentiation potential of rat adipose tissue-derived stem cells. Gen Physiol Biophys. 2011;30:167-74.

10. Malladi $P, X u Y$, Yang GP, Longaker MT. Functions of vitamin D, retinoic acid, and dexamethasone in mouse adipose-derived mesenchymal stem cells. Tissue Eng. 2006;12:2031-40.

11. Skillington J, Choy L, Derynck R. Bone morphogenetic protein and retinoic acid signaling cooperate to induce osteoblast differentiation of preadipocytes. J Cell Biol. 2002;159:135-46.

12. Wan DC, ShiYY, Nacamuli RP, Quarto N, Lyons KM, Longaker MT. Osteogenic differentiation of mouse adipose-derived adult stromal cells requires retinoic acid and bone morphogenetic protein receptor type IB signaling. PNAS. 2006;103:12335-40.

13. Knippenberg M, Helder MN, Zandieh DB, Wuisman PI, Klein-Nulend J. Osteogenesis versus chondrogenesis by BMP-2 and BMP-7 in adipose stem cells. Biochem Biophys Res Commun. 2006;342:902-8.

14. Levi B, James AW, Wan DC, Glotzbach JP, Commons GW, Longaker MT. Regulation of human adipose-derived stromal cell osteogenic differentiation by insulin-like growth factor-1 and platelet-derived growth factor- $\alpha$. Plast Reconstr Surg. 2010a;126:41-52.

15. Levi B, James AW, Xu Y, Commons GW, Longaker MT. Divergent modulation of adipose-derived stromal cell differentiation by TGF- $\beta$ based on species of derivation. Plast Reconstr Surg. 2010b;126:412-25.

16. Song HW, Jeon ES, Kim JI, Jung JS, Kim JH. Oncostatin M promotes osteogenesis and suppresses adipogenic differentiation of human adipose tissue-derived mesenchymal stem cells. J Cell Biochem. 2007;101:1238-51.

17. Huang SC, WuTC, Yu HC, Chen MR, Liu CM, Chiang WS, et al. Mechanical strain modulates age-related changes in the proliferation and differentiation of mouse adipose-derived stromal cells. BMC Cell Biol. 2010;11:1-14.

18. Boeloni JN, Ocarino NM, Bozzi A, Silva JF, Castanheira P, Goes $A M$, et al. Dose-dependent effects of triiodothyronine on osteogenic differentiation of rat bone marrow mesenchymal stem cells. Horm Res. 2009;71:88-97.

19. Ortega FJ, Moreno-Navarrete JM, Ribas V, Esteve E, Rodriguez-Hermosa JI, Ruiz B, et al. Subcutaneous fat shows higher thyroid hormone receptor- $\alpha 1$ gene expression than omental fat. Obesity; $17: 2134-41$.

20. Chen NC, Hausman GJ, Wright JT. Hormonal regulation of insulin-like growth factor binding proteins and insulin-like growth factor I (IGF-I) secretion in porcine stromal-vascular cultures. J Anim Sci. 1996;74:2369-75.

21. Serakides R, Nunes VA, Ocarino NM, Nascimento EF. Efeito da associação hipertireoidismo-castração no osso de ratas adultas. Arq Bras Endocrinol Metab. 2004;48:875-84.

22. Gomide V, Zonari AAC, Breyner NM, Goes AM, Pereira MM. Attachment and proliferation of human-adipose-tissue-derived stem cells on bioactive glass/PVA hybrid scaffolds. ISRN Materials Science, 2011 (no prelo).

23. Ishii M, Koike $C$, Igarashi A, Yamanaka K, Pan H, Higashi $Y$, et al. Molecular markers distinguish bone marrow mesenchymal stem cells from fibroblasts. Biochem Biophys Res Commun. 2005a;332:297-303.

24. Valério P, Pereira MM, Goes AM, Leite MF. The effect of ionic products from bioactive glass dissolution on osteoblast proliferation and collagen production. Biomaterials. 2004;25:2941-8.

25. Ishida H, Bellows CG, Aubin JE, Heersche JN. Tri-iodothyronine (T3) and dexamethasone interact to modulate osteoprogenitor cell differentiation in fetal rat calvaria cell cultures. Bone. 1995;16:545-9.

26. Ocarino NM, Boeloni JN, Goes AM, Silva JF, Marubayashi U, Serakides $R$. Osteogenic differentiation of mesenchymal stem cells from osteopenic rats subjected to physical activity with and without nitric oxide synthase inhibition. Nitric Oxide. 2008;19:320-5.

27. Prophet EB, Mills B, Arrington JB, Sobin LH. Laboratory Methods in Histotechnology. Washington DC: Armed Forces Institute of Pathology; 1992. p. 278.

28. Ocarino NM, Boeloni JN, Jorgetti V, Gomes DA, Goes AM, Serakides R. Intra-bone marrow injection of mesenchymal stem cells improves the femur bone mass of osteoporotic female rats. Connect Tissue Res. 2010;51:426-36.

29. Sampaio IBM. Estatística aplicada à experimentação animal. Belo Horizonte: FEP/MVZ; 1998. p. 211.

30. Schäffler A, Büchler $C$. Concise review: adipose tissue-derived stromal cells - basic and clinical implications for novel cell-based therapies. Stem Cells. 2007;25:818-27.

31. Bobis S, Jarocha D, Majka M. Mesenchymal stem cells: characteristics and clinical applications. Folia Histochem Cytobiol. 2006;44:215-30.

32. Roebuck KA, Finnegan A. Regulation of intercellular adhesion molecule-1 (CD54) gene expression. J Leukoc Biol. 1999;66:876-88.

33. Payushina OV, Domaratskaya El, Starostin VI. Mesenchymal stem cells: sources, phenotype, and differentiation potential. Cell Biol. 2006;33:2-18.

34. Mueller SM, Glowacki J. Age-related decline in the osteogenic potential of human bone marrow cells cultured in three-dimensional collagen sponges. J Cell Biochem. 2001;82:583-90.

35. Kretlow JD, Jin YQ, Liu W, Zhang WJ, Hong TH, Zhou G, et al. Donor age and cell passage affects differentiation potential of murine bone marrow-derived stem cells. BMC Cell Biol. 2008;9:1-13.

36. Roobrouck VD, Ulloa-Montoya F, Vervaillie CM. Self-renewal and differentiation capacity of young and aged stem cells. Exp Cell Res. 2008;314:1937-44.

37. Zhang W, Ou G, Hamrick M, Hill W, Borke J, Wenger K, et al. Age-related changes in the osteogenic differentiation potential of mouse bone marrow stromal cells. J Bone Miner Res. 2008;23:1118-28.

38. Zhou S, Greenberger JS, Epperly MW, Goff JP, Adler C, Leboff $\mathrm{MS}$, et al. Age-related intrinsic changes in human bone-marrow derived mesenchymal stem cells and their differentiation to osteoblasts. Aging Cell. 2008;7:335-43.

39. Hell RCR, Ocarino NM, Boeloni JN, Silva, JF, Goes AM, Santos RL, et al. Physical activity improves age-related decline in the osteogenic potential of rats bone-marrow derived mesenchymal stem cells. Acta Physiol (Oxf). 2012;205(2):292-301.

40. Zhu M, Kohan E, Bradley J, Hedrick M, Benhaim P, Zuk P. The effect of age on osteogenic, adipogenic and proliferative potential of female adipose-derived stem cells. J Tissue Eng Regen Med. 2009;3:290-301.

41. Shi YY, Nacamuli RP, Salim A, Longaker MT. The osteogenic potential of adipose-derived mesenchymal cells is maintained with aging. Plast Reconstr Surg. 2005;116:1686-96. 
42. Peptan IA, Hong L, Mao JJ. Comparison of osteogenic potentials of visceral and subcutaneous adipose-derived cells of rabbits. Plast Reconstr Surg. 2006;117:1462-70.

43. Toyoda M, Matsubara Y, Lin K, Sugimachi K, Furue M. Characterization and comparison of adipose tissue-derived cells from human subcutaneous and omental adipose tissues. Cell Biochem Funct. 2009;27:440-7.

44. Levi B, Nelson ER, Brown K, James AW, Xu D, Dunlevie R, et al. Differences in osteogenic differentiation of adipose-derived stromal cells from murine, canine, and human sources in vitro and in vivo. Plast Reconstr Surg. 2011;128:373-86.

45. Chou YF, Zuk PA, Chang TL, Benhaim P, Wu BM. Adipose-derived stem cells and BMP2: part 1. BMP2-treated adipose-derived stem cells do not improve repair of segmental femoral defects. Connect Tissue Res. 2011;52:109-18.

46. Zuk P, Chou YF, Mussano F, Benhaim P, Wu BM. Adipose-derived stem cells and BMP2: part 2. BMP2 may not influence the osteogenic fate of human adipose-derived stem cells. Connect Tissue Res. 2011;52:119-32.

47. Song I, Kim BS, Kim CS, Im GI. Effects of BMP-2 and vitamin D3 on the osteogenic differentiation of adipose stem cells. Biochem Biophys Res Commun. 2011;408:126-31.

48. Panetta NJ, Gupta DM, Lee JK, Wan DC, Commons GW, Longaker MT. Human adipose-derived stromal cells respond to and elaborate bone morphogenetic protein-2 during in vitro osteogenic differentiation. Plast Reconstr Surg. 2010;125:483-93.

49. Dieudonné MN, Leneveu MC, GiudicelliYA, Pecquery R. Evidence for functional estrogen receptors alpha and beta in human adipo- se cells: regional specificities and regulation by estrogens. Am J Physiol Cell Physiol. 2004;286:C655-61.

50. Mirsaidi A, Kleinhans KN, Rimann M, Tiaden AN, Stauber M, Rudolph $\mathrm{KL}$, et al. Telomere length, telomerase activity and osteogenic differentiation are maintained in adipose-derived stromal cells from senile osteoporotic SAMP6 mice. J Tissue Eng Regen Med. 2012;6(5):378-90.

51. Hong L, Colpan A, Peptan IA. Modulations of $17-\beta$ estradiol on osteogenic and adipogenic differentiations of human mesenchymal stem cells. Tissue Eng. 2006;12:2747-53.

52. Thomas T, Gori F, Khosla S, Jensen MD, Burquera B, Riggs BL. Leptin acts on human marrow stromal cells to enhance differentiation to osteoblasts and to inhibit differentiation to adipocytes. Endocrinology. 1999;140:1630-8.

53. Shimizu H, ShimomuraY, NakanishiY, FutawatariT, Ohtani K, Sato $\mathrm{N}$, et al. Estrogen increases in vivo leptin production in rats and human subjects. J Endocrinol. 1997;154:285-92.

54. Zhou S, Zilberman Y, Wassermann K, Bain SD, Sadovsky Y, Gazit D. Estrogen modulates estrogen receptor $\alpha$ and $\beta$ expression, osteogenic activity, and apoptosis in mesenchymal stem cells (MSCs) of osteoporotic mice. J Cell Biochem. 2001;81:144-55.

55. Chen XD, Dusevich V, Feng JQ, Manolagas SC, Jilka RL. Extracellular matrix made by bone marrow cells facilitates expansion of marrow-derived mesenchymal progenitor cells and prevents their differentiation into osteoblasts. J Bone Miner Res. 2007;22:1943-56.

56. O'Shea PJ, Williams GR. Insight into the physiological actions of thyroid hormone receptors from genetically modified mice. J Endocrinol. 2002;175:553-70. 